\title{
Temporal Change of Environmental Contamination Conditions in Five Years after the Fukushima Accident
}

\author{
Kimiaki Saito, ${ }^{1, a}$ \\ ${ }^{1}$ Japan Atomic Energy Agency, Fukushima Environmental Safety Center, 2-2-2 Uchisaiwai-cho, Chiyoda-ku, Tokyo 100-8577, Japan
}

\begin{abstract}
The temporal change of environmental contamination conditions after the Fukushima accident have been clarified based on large-scale environmental monitoring data repeatedly obtained in the $80 \mathrm{~km}$ zone. The decreasing tendency of air dose rates was confirmed to obviously depend on land uses. In human-related diverse environments the air dose rates have decreased much faster than the physical decay of radiocesium. The horizontal movement of radiocesium in undisturbed fields were found to be generally quite small, though it has gradually penetrated into the deeper parts of the ground.
\end{abstract}

\section{Introduction}

In the Fukushima accident, a large amount of radionuclides were released into the atmosphere and deposited over wide areas in East Japan. In order to obtain reliable and detailed environmental radiation data, large-scale environmental monitoring activities have been repeatedly performed in collaboration with many organizations in so-called mapping projects commissioned by the national government $[1,2]$. The data on air dose rates and radionuclide ground deposition accumulated in the projects have clarified the characteristics of the contamination conditions around the Fukushima site and their temporal changes. This paper summarizes the obtained results.

\section{Large-scale environmental monitoring}

\subsection{Dose rate in air}

Dose rates in air in terms of ambient dose equivalent rates have been measured in large scale mainly using the following five methods. The first four methods have been utilized in the mapping projects [1.2] and the last helicopter surveys have been conducted in other projects [3].

\subsubsection{Fixed-location measurements above undisturbed flat fields}

Air dose rates are measured with calibrated survey meters above undisturbed fields where the conditions are expected not to change for a long-time. The measurements aims to investigate natural weathering

\footnotetext{
${ }^{\mathrm{a}}$ Corresponding author:saito.kimiaki@jaea.go.jp
}

effects in reference locations. At about 6,500 locations in the $80 \mathrm{~km}$ zone, the measurements are being performed.

\subsubsection{Car-borne survey on roads}

Car-borne surveys are carried out over wide areas in East Japan [4] with a mobile survey system KURAM-II [5]. Simultaneous usage of more than one hundred systems in collaboration with municipalities enabled us to construct an air dose rate map over wide areas within a short time. A total distance of $30,000-80,000 \mathrm{~km}$ in East Japan have been covered in each survey.

\subsubsection{Walk survey in human-related environments}

In a walk survey, a person carrying a KURAMA-II system walks around in diverse environments related to human activities. Walk surveys provide important data from a viewpoint of exposure doses to inhabitants. About 600 areas of $1 \mathrm{~km}$ square in the $80 \mathrm{~km}$ zone are selected for walk surveys.

\subsubsection{Unmanned helicopter survey}

Unmanned helicopter surveys are employed to obtain data in the $5 \mathrm{~km}$ zone where crews are difficult to enter on land [6]. This method has better positional resolution than usual helicopter survey since the flying height is about $80 \mathrm{~m}$.

\subsubsection{Helicopter survey}

Helicopter surveys have targeted for wide areas ranging from the $80 \mathrm{~km}$ zone to the whole Japan depending on the campaign. This method can obtain data over wide areas even though the data contain some uncertainties. 


\subsection{Radionuclides ground deposition}

Radionuclide deposition densities in $\mathrm{Bq} / \mathrm{m}^{2}$ and depth profiles in $\mathrm{Ba} / \mathrm{kg}$ for different soil layers have been investigated.

\subsubsection{Radionuclide deposition density}

In the first campaign, more than 11,000 soil samples were collected at more than 2,200 locations within the $100 \mathrm{~km}$ zone and the rest of Fukushima prefecture [7,8]. In principle, five samples were collected at one location. The collected soil samples were analysed at 22 institutes using Ge detectors for gamma-emitting radionuclides. Further, selected one hundred samples were analysed for alpha- and beta- emitting radionuclides.

Since the second campaign, in situ measurements with a portable Ge detector have been utilized which can determine the average deposition density of a location by detecting gamma rays from wide area [9].

\subsubsection{Depth profile}

Soil samples for different depth layers are collected using a scraper plate which can minimize cross contaminations among the samples [10]. The thickness of collected soil layer is changed from $5 \mathrm{~mm}$ to a few $\mathrm{cm}$ according to the condition. Collected samples are analysed using a $\mathrm{Ge}$ detector.

\section{Initial contamination conditions}

Among many radionuclides released from the Fukushima accident, the following radionuclides were detected in soil at a number of locations sufficient to show on a map: ${ }^{134} \mathrm{Cs},{ }^{137} \mathrm{Cs},{ }^{131} \mathrm{I},{ }^{132 \mathrm{~m}} \mathrm{Te},{ }^{129 \mathrm{~m}} \mathrm{Ag},{ }^{89} \mathrm{Sr}$, ${ }^{90} \mathrm{Sr},{ }^{238} \mathrm{Pu},{ }^{239+240} \mathrm{Pu}$. A part of detected strontium and plutonium were judged to originate from the accident on the basis of their isotope ratios; however, the deposition densities were comparable to the levels of background radionuclides due to the nuclear weapon tests.

Effective doses for 50 years due to deposited radionuclides were conservatively evaluated from the observed maximum deposition densities using dose conversion coefficients shown in TECDOC-1162 [11]. Radiocesium were confirmed to be far more important than other radionuclides from a dosimetric point of view. The doses from radiostrontium and plutonium were negligible in comparison.

The total deposition amount of ${ }^{137} \mathrm{Cs}$ on the Japanese main island was estimated based on the results of the first and second campaigns as of June 2011 and March 2012, respectively. The first campaign targeted the region near Fukushima prefecture [7], while the second campaign covered wide areas in East Japan with in situ measurements [9]. These data were integrated together with helicopter survey data. It was estimated that $1.6 \times 10^{15} \mathrm{~Bq}$ of ${ }^{137} \mathrm{Cs}$ was deposited within the $80 \mathrm{~km}$ zone and $2.0 \times 10^{15} \mathrm{~Bq}$ on the main island. The total release of ${ }^{137} \mathrm{Cs}$ have been evaluated by several researchers; in most cases, the evaluated release was a little larger than $1 \times 10^{16} \mathrm{~Bq}$ [12]. Therefore, it is considered that about $20 \%$ or a little less of the released ${ }^{137} \mathrm{Cs}$ was deposited on land in Japan.

The proportion of ${ }^{137} \mathrm{Cs}$ deposition for each land use to the total deposition was calculated within the $80 \mathrm{~km}$ zone referring to the National Land Numerical Information [13]. Forested areas occupy a large part of Fukushima prefecture. The proportion of ${ }^{137} \mathrm{Cs}$ deposition was found to be proportional to the area if we consider the whole $80 \mathrm{~km}$ zone: About $70 \%$ of ${ }^{137} \mathrm{Cs}$ was estimated to be deposited in forest; $20 \%$ in agricultural land; $5 \%$ in building site. The feature is different when we consider a smaller region. For example, in case of Fukushima city, the proportion of deposition in building site was as twice as that expected from the area.

\section{Temporal changes}

Temporal changes of contamination conditions were analysed in the $80 \mathrm{~km}$ zone having severe contamination on the basis of large-scale environmental monitoring data accumulated from 2011 to 2015 [1].

\subsection{Dose rate in air}

The decreasing tendency of dose rates in air was quite different due to the condition. Figure 1 indicates the timedependent average air dose rates measured by different methods. Roughly speaking, the air dose rate above roads measured by car-borne surveys became $1 / 5$ in four years since June 2011; that above undisturbed flat fields became $1 / 4$; while, the air dose rate was estimated not to decrease up to $2 / 5$ simply with the physical deay.

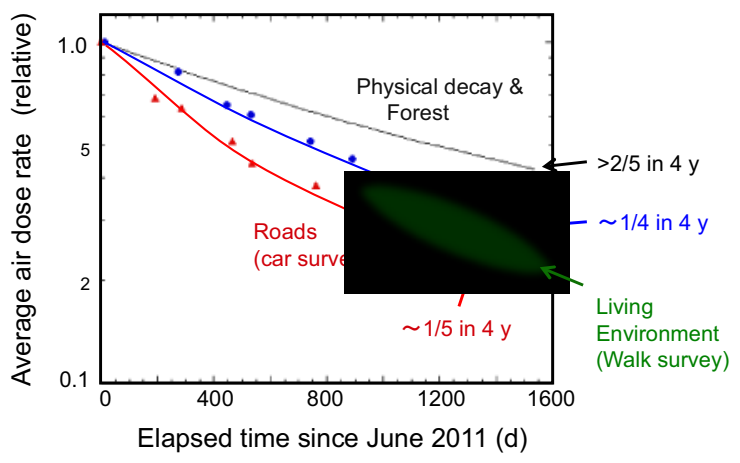

Figure 1. Decreasing tendency of the average air dose rate

Since walk surveys started in 2013, this kind of estimation is impossible; nevertheless, it has been made clear that air dose rates by walk surveys are higher than those above roads and lower than those above undisturbed flat fields on average. Thus, air dose rates in environments related to human activities were found to have decreased much faster than the physical decay of radiocesium.

In contrast, air dose rates in pure forest were found to have decreased nearly according to the physical decay as a whole, though the species of trees may slightly affect the decreasing tendency. The average air dose rate measured by helicopter surveys was reported to have 
become $1 / 3$ in four years. This is because the helicopter surveys cover the whole area in the $80 \mathrm{~km}$ zone including wide forested areas.

Statistical analyses of car-borne data suggested two important factors affecting the reduction tendency of air dose rates: land uses and human activities. It is already well-known in the past studies that land uses affect the air dose rate reduction tendency. The knowledge obtained after the Chernobyl accident has been summarized as location factors which define time-dependent air dose rate reduction for different land uses [14].

Generally, the location factors have been determined by a limited number of data; therefor, the predicted air dose rates with current location factors have some uncertainties. In the studies performed after the Fukushima accident, massive car-borne survey data have been statistically analyzed, and this enabled to predict the air dose rate trend for each land use with the confidential intervals [15].

The air dose rate reduction tendency is obviously different between inside and outside the evacuation zone even if areas with the same land use are compared. This suggests that human activities are an important factor which decides air dose reduction; however, comprehensive quantitative analysis has not been done in connection with statistical quantities, which must be a future challenge.

\subsection{Radionuclide deposition}

\subsubsection{Deposition density}

Radiocesium deposition densities in undisturbed flat fields in terms of $\mathrm{Bq} / \mathrm{m}^{2}$ were analysed excluding the locations where decontamination activities were considered to be performed or ground conditions were changed somehow. Figure 2 gives the time-dependent average deposition densities for ${ }^{134} \mathrm{Cs}$ and ${ }^{137} \mathrm{Cs}$. For the both nuclides, the deposition density has decreased according to the physical decay. It is inferred that the movement of radiocesium in horizontal directions in undisturbed fields is quite small.

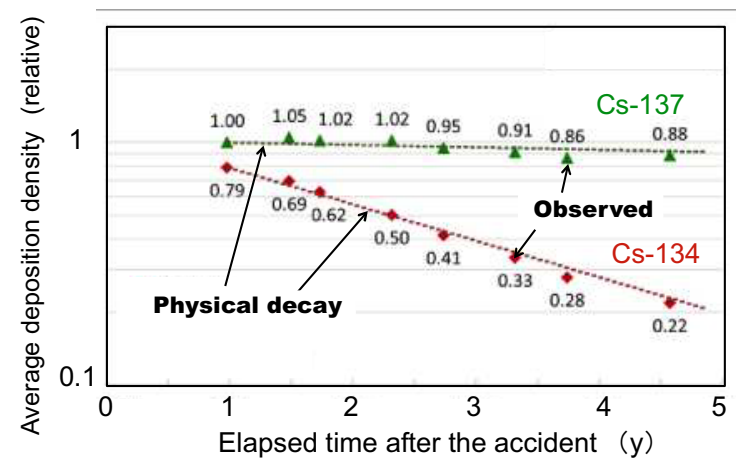

Figure 2. Time-dependent radiocesium deposition density

The knowledge obtained from radiocesium migration studies supports this tendency. It was found in the field measurements that soil erosion plays an important role in radiocesium migration in the natural environment but an annual radiocesium discharge rate is very small, generally an order of $0.1 \%$ or less [1].

\subsubsection{Depth profile}

Two kinds of typical depth profiles in undisturbed fields have been observed in the $80 \mathrm{~km}$ zone. The first one is an exponential distribution where the radiocesium concentration decreases monotonously with depth. The other is a distribution having a concentration peak at a certain depth. The latter distribution was found to be well approximated by a hyperbolic secant (sech) function [10]. Further, in some locations, disturbed distributions were found. Most of these disturbed distributions were considered due to decontamination activities or some human activities to change the ground conditions.

The $90 \%$ depth $\left(\mathrm{L}_{90}\right)$ defined as the depth up to which $90 \%$ of deposited radiocesium exist was calculated for the all depth profiles except disturbed distributions. Figure 3 indicates the observed $90 \%$ depths as a function of elapsed time. The whole data are shown by red or blue marks, and the average at each sampling time is by a green mark. Though the average $\mathrm{L}_{90}$ has increased with time, the average $\mathrm{L}_{90}$ in 2015 was still smaller than $5 \mathrm{~cm}$. Decontamination by removing soil up to a depth of $5 \mathrm{~cm}$ is considered to be effective even now.

The penetration of deposited radiocesium into the ground has increased the shielding effect of soil for gamma rays. This is the main reason that air dose rates above undisturbed fields have reduced faster than the physical decay.

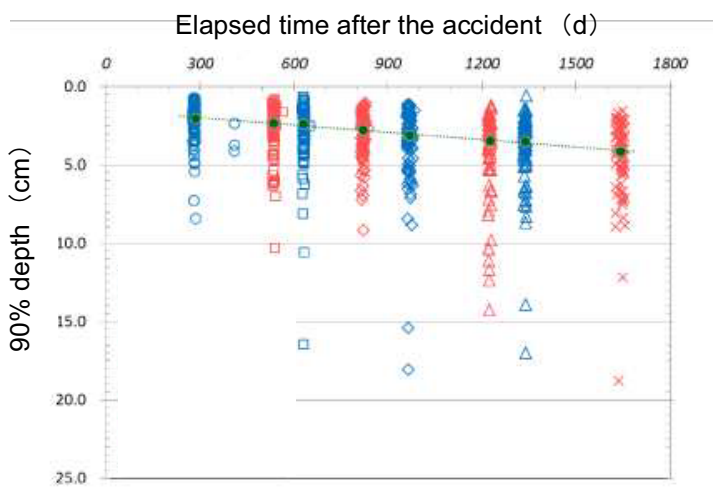

Figure 3. Increase of $\mathrm{L}_{90}$ with elapsed time

\section{Conclusion}

A huge amount of data periodically obtained in the mapping projects after the Fukushima accident have clarified the specific features of the time-dependent contamination conditions. The dose rate reduction was found to depend on land uses and human activities. The air dose rates in diverse environments connected with human living have decreased much faster than the physical decay of radiocesium. On the other hand, in pure forest environments, air dose rates have decreased according to the physical decay. The horizontal movement of radiocesium deposited on undisturbed fields 
is small while gradually penetrating into the ground. This results in air dose rate reduction faster than the physical decay because of increase in gamma-ray shielding effect by soil.

\section{Acknowledgement}

The data indicated in this paper are mainly from the mapping projects funded by the Ministry of Education, Sports, Science and Technology (MEXT) and by the Nuclear Regulation Authority (NRA).

\section{References}

1. NRA, http://radioactivity.nsr.go.jp/ja/list/338/list1.html (in Japanese)

2. K. Saito, Y. Onda, J. Environ. Radioact. 139, 240249 (2015).

3. MEXT, http://fukushima.jaea.go.jp/initiatives/cat03/

4. M. Ando, Y. Nakahara, S. Tsuda, T. Yoshida, N. Matsuda, F. Takahashi, S. Mikami, N. Kinouchi, T. Sato, M. Tanigaki, K. Takamiya, N. Sato, R. Okumura, Y. Uchihori, K. Saito, J. Environ. Radioact. 139, 266-280 (2015)

5. S. Tsuda, T. Yoshida, K.Saito, J. Environ. Radioact. 139, 260-265 (2015)

6. Y. Sanada, T. Torii, J. Environ. Radioact. 139, 294299 (2015)

7. K. Saito, I. Tanihata, M. Fujiwara, T. Saito, S.

Shimoura, T. Otsuka, Y. Onda, M. Hoshi, Y.

Ikeuchi, F. Takahashi, N. Kinouchi, J. Saegusa, A.

Seki, H. Takemiya, T. Shibata, J. Environ. Radioact. 139, 308-319 (2015)

8. Y. Onda, H. Kato, M. Hoshi, Y. Takahashi, M. Nguyen, J. Environ. Radioact. 139, 300-307 (2015)

9. S. Mikami, T. Maeyama, Y. Hoshide, R. Sakamoto, S. Sato, N. Okuda, S. Demongeot, R. Gurriaran, Y. Uwamino, H. Kato, M. Fujiwara, T. Sato, H. Takemiya, K. Saito, J. Environ. Radioact. 139, 320343 (2015).

10. N. Matsuda, S. Mikami, S. Shimoura, J. Takahashi, M. Nakano, K. Shimada, K. Uno, S. Hagiwara, K Saito, J. Environ. Radioact. 139, 427-434 (2015).

11. IAEA, TECDOC-1162 (2000)

12. TEPCO, http://www.tepco.co.jp/cc/press/betu12 j/images/120 524j0105.pdf (2012)

13. MLIT, http://nlftp.mlit.go.jp/ksj-e/index.html

14. EC, EUR 16541 EN (1996)

15. S. Kinase, T. Takahashi, S. Sato, R. Sakamoto, K. Saito, Radiat. Prot. Dosim. 160, 318-324 (2014) 